\title{
The role of fibrin deposition in diabetic glomerulosclerosis: a light, electron and immunofluorescence microscopy study
}

\author{
A. FARQUHAR, MARY K. MacDONALD, AND J. T. IRELAND \\ From the Department of Pathology, University of Edinburgh
}

SYNOPSIS The possible role of fibrin deposition in the development of diabetic glomerulosclerosis has been investigated by light, immunofluorescence, and electron microscopy examination of renal tissue obtained by percutaneous biopsy from seven diabetic patients having minimal clinical evidence of renal involvement and at necropsy on nine diabetic patients. Although the biopsy specimens showed only early to moderate diffuse glomerulosclerosis without either nodular or exudative lesions, approximately $70 \%$ of glomeruli examined showed specific fluorescence for fibrinogen in a discontinuous linear pattern along the capillary basement membrane and diffusely in the mesangium. Moreover the immunofluorescence findings correlated well with the distribution patterns of material thought to be fibrin both in the light microscopy studies, by virtue of its staining properties, and by electron microscopy, because of periodicity, texture, and electron density. It is suggested that electron-dense granular deposits seen on electron microscopy may represent intermediate compounds in the fibrinogen to fibrin conversion, and that endothelial and mesangial trapping of fibrinogen or other macromolecules may initiate or accelerate mesangial enlargement, nodule formation, and irregularity of the basement membrane.

There is much evidence to suggest that the microvasculature in diabetic subjects is hyperpermeable to certain plasma constituents (Lendrum, 1963; Davies, Woolf, and Carstairs, 1966; Berkman and Rifkin, 1966; Fisher, Perez-Stable, Amidi, Sarver, and Danowski, 1967; Larsson. 1967; Balodimos, Chlouverskis, Gleason, Jarrett, Kahn, Keen, and Soeldner, 1971). Although the nature and onset of the early structural changes in the glomerular capillaries remain controversial, it is possible that altered permeability may precede the lesions seen on light and electron microscopy (Ditzel and Schwartz, 1967; Trap-Jensen, Alport, Garcia del Rio, and Lassen, 1967). Other investigations suggest that a hypercoagulable state, manifest by increased platelet adhesiveness (Shaw, Pegrum, Wolff, and Ashton, 1967; Abastado, Doumenc, Prost, Bara, Samama, Dérot, and Bousser, 1968), elevated plasma fibrinogen levels (Egeberg, 1963; Valdorf-Hansen, 1967), and diminished fibrinolytic activity (Fearnley, Chakrabarti, and Avis, 1963; Cash and McGill, 1969; Sharma and Malhotra, 1969) may develop in some diabetic patients.

Received for publication 20 April 1972.
In the light of these two major aspects, and in view of the increasing importance attached to fibrinogen and related products in human and experimental glomerulopathies (McCluskey, 1969; Clarkson, MacDonald, Petrie, Cash, and Robson, 1971), the possible role of fibrin deposition in the development of diabetic glomerulosclerosis was investigated by light, immunofluorescence, and electron microscopy examination of renal tissue.

\section{Materials and Methods}

Renal tissue was obtained by percutaneous biopsy using a Franklin-modified Vim-Silverman needle from seven diabetic patients having minimal clinical evidence of renal involvement and at necropsy on nine diabetic patients within 24 hours of death (Table I). Control tissue was obtained from necropsies on six non-diabetic patients who had shown no clinical evidence of renal or metabolic disease.

BIOPSY TISSUE

Two cores of tissue were obtained from each patient, one providing material for electron microscopy and 


\begin{tabular}{|c|c|c|c|c|c|c|}
\hline Case & Age & $\operatorname{Sex}$ & $\begin{array}{l}\text { Duration of Diabetes \& } \\
\text { Treatment }\end{array}$ & $\begin{array}{l}\text { Endogenous Creatinine } \\
\text { Clearnance ( } \mathrm{ml} / \mathrm{min})\end{array}$ & $\begin{array}{l}\text { Urinary Protein for } 24 \\
\text { Hours }\end{array}$ & Blood Pressure ( $\mathrm{mm} \mathrm{Hg}$ ) \\
\hline \multicolumn{7}{|c|}{ Biopsies } \\
\hline 1 & 45 & $\mathbf{M}$ & 5 yr Tolbutamide & 110 & $500 \mathrm{mg}$ & $140 / 100$ \\
\hline 2 & 50 & $\mathbf{M}$ & 14 yr Insulin & 85 & $700 \mathrm{mg}$ & $130 / 90$ \\
\hline 3 & 31 & $\mathbf{M}$ & 17 yr Insulin & 95 & $300 \mathrm{mg}$ & $140 / 90$ \\
\hline 4 & 49 & $\mathbf{M}$ & 5 yr Insulin & 97 & $650 \mathrm{mg}$ & $130 / 80$ \\
\hline 5 & 48 & $\mathbf{M}$ & 12 yr Insulin & 124 & $250 \mathrm{mg}$ & $135 / 90$ \\
\hline 6 & 66 & $\mathbf{M}$ & ?2 mth Diet & 78 & $600 \mathrm{mg}$ & $125 / 80$ \\
\hline 7 & 55 & $\mathbf{M}$ & 19 yr Insulin & 66 & $550 \mathrm{mg}$ & $60 / 90$ \\
\hline \multicolumn{7}{|c|}{ Necropsies } \\
\hline 8 & 67 & $\mathbf{M}$ & 5 yr Insulin & Data not available & Data not available & $180 / 110$ \\
\hline 9 & 69 & $\mathbf{F}$ & 26 yr Insulin & Data not available & Data not available & $150 / 100$ \\
\hline 10 & 63 & $\mathbf{F}$ & 7 yr Insulin & Data not available & Data not available & $140 / 100$ \\
\hline 11 & 63 & $\mathbf{F}$ & 24 yr Insulin & 34 & $2 \mathrm{~g}$ & $180 / 120$ \\
\hline 12 & 74 & $\mathbf{F}$ & 21 yr Insulin & Data not available & Data not available & $160 / 100$ \\
\hline 13 & 52 & $\mathbf{F}$ & 9 yr Insulin & Data not available & Data not available & $130 / 90$ \\
\hline 14 & 72 & $\mathbf{F}$ & $11 \mathrm{yr}$ Insulin & Data not available & Data not available & $160 / 100$ \\
\hline 15 & 69 & $\mathbf{M}$ & 2 yr Diet & Data not available & Data not available & $150 / 100$ \\
\hline 16 & 79 & $\mathbf{F}$ & 41 yr Insulin & Data not available & Data not available & $140 / 90$ \\
\hline
\end{tabular}

Table I Clinical data

for thick-section studies by light microscopy using modified haematoxylin and eosin, MSB, and PicroMallory stains, the other for immunofluorescence studies. Blocks for electron microscopic examination were fixed in Palade's $1 \%$ buffered osmic acid, dehydrated in alcohol and embedded in Araldite. Using the method of Mayor, Hampton, and Rosario (1961) for de-Aralditing, 0.5-1.5 $\mu$ thickness sections were cut for light microscopy also. For electron microscopy ultrathin sections were cut on a PorterBlum MT2 ultramicrotome, stained with uranyl acetate and Reynold's lead citrate, and viewed in an AEI EM6 electron microscope.

After freezing, the second core of tissue for immunofluorescence studies was sectioned at 2 to $3 \mu$ and fixed in $95 \%$ ethanol for 10 minutes. If not immediately required, the frozen sections were stored at $-20^{\circ} \mathrm{C}$. Frozen sections were stained with FITC conjugated antihuman fibrinogen serum after the method of Nairn (1969).

\section{NECROPSY TISSUE}

Small blocks of cortical tissue were fixed in formolcorrosive for two to 10 hours, dehydrated in alcohol, and embedded in Araldite for thick section studies by light microscopy. Tissue was taken for immunofluorescence investigation also and treated as described above.

\section{Results}

\section{LIGHT MICROSCOPY}

The general morphological features observed in glomeruli were in agreement with those recorded in the literature and referred to as diabetic glomerulosclerosis (Ireland, 1971). All biopsy specimens showed early to moderate diffuse glomerulosclerosisç but no nodular or exudative lesions were evident. $\stackrel{\text { क }}{\rightarrow}$ In the necropsy tissue, cases 9,15 , and 16 showed, in $\vec{\varphi}$ addition to moderate arteriosclerosis and diffuse glomerular lesions, nodular changes and extensive exudative lesions of the 'fibrin cap' and 'capsular drop' type. The remaining cases showed only moderate diffuse glomerulosclerosis with the exception of case 10 which had arteriosclerosis in addition.

In de-Araldited sections, though staining was often $\odot$ faint, differentiation of the lesions and structural $\overrightarrow{0}$ relationships in the glomerular capillaries was 3 facilitated. Patchy areas staining as fibrin were

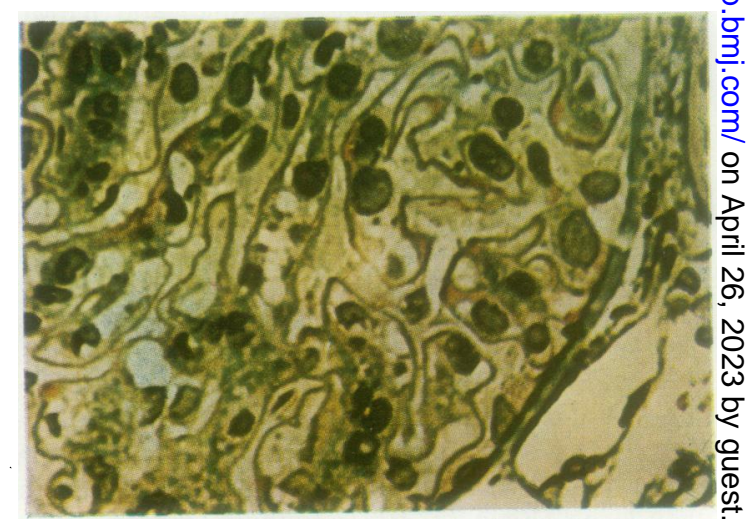

Fig. 1 Case 1 The biopsy tissue was embedded in Araldite, the section de-Araldited with sodium methoxide and stained by the MSB method. This part of a glomerulus shows red staining, corresponding to fibrin, scattered irregu!arly along capillary walls and also in mesangial regions. $\times 800$ 


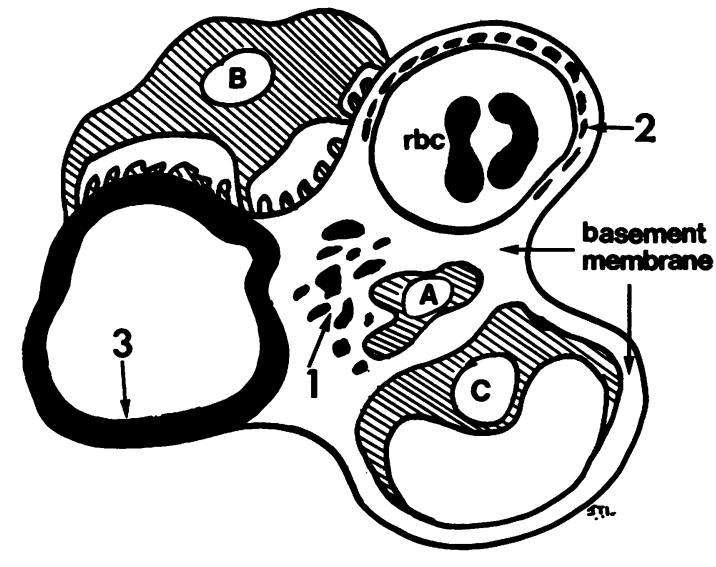

Fig. 2 Diagram of glomerular capillary lobule showing patterns of distribution of fibrin.

1 Granular fibrin scattered within mesangium.

2 Beaded in discontinuous linear distribution either subendothelial or within basement membrane.

3 Diffuse: uniform throughout capillary wall. A Mesangial cell; $B$ Epithelial cell attached by foot processes; C Endothelial cell within capillary lumen. frequently found within mesangial regions and also in a fine, discontinuous linear pattern along the inner aspect of the capillary walls (Fig. 1). Often these areas of positive staining seemed unrelated to any local glomerular damage, and on occasion represented the only lesion evident apart from an unequivocal increase in mesangial mass.

\section{FLUORESCENCE MICROSCOPY}

In each case approximately 10 glomeruli were examined. Grading of the intensity of fluorescence was on an arbitrary semiquantitative three-point scale $(0,+,++)$. The distribution of fluorescence was recorded as granular, beaded, or diffuse (Fig. 2). Approximately $70 \%$ of all glomeruli showed positive staining; the degree of immunofluorescence in different glomeruli varied quantitatively as summarized in Table II. Specific fluorescence was found most constantly in a beaded pattern along the capillary wall or in the mesangial regions (Fig. 3).

\section{ELECTRON MICROSCOPY}

In every biopsy thickening of the glomerular capillary basement membrane was the most prominent change seen (Fig. 4). Thus the mean basement membrane thickness in individual patients ranged from $2750 \mathrm{~A}^{\circ}$ to $8000 \mathrm{~A}^{\circ}$, whereas in non-diabetic

\begin{tabular}{|c|c|c|c|c|c|c|}
\hline Case & Fluorescence & Mesangial Region & Capillary Wall & Nodule & Exudative Lesion & Arteriole \\
\hline \multicolumn{7}{|c|}{ Biopsies } \\
\hline 1 & $\begin{array}{l}\mathbf{I} \\
\mathbf{P}\end{array}$ & $\begin{array}{l}++ \\
\text { Patchy-granular }\end{array}$ & $\begin{array}{l}++ \\
\text { Beaded }\end{array}$ & 0 & $\mathbf{0}$ & $\begin{array}{l}0 \\
\text { Diffuse }\end{array}$ \\
\hline 3 & $\mathbf{I}$ & $\begin{array}{l}++ \\
\text { Patchy-granular }\end{array}$ & $\begin{array}{l}++ \\
\text { Beaded }\end{array}$ & 0 & $\mathbf{0}$ & 0 \\
\hline 5 & $\mathbf{I}$ & $\begin{array}{l}++ \\
\text { Patchy-granular }\end{array}$ & $\begin{array}{l}++ \\
\text { Beaded }\end{array}$ & 0 & $\mathbf{0}$ & $\mathbf{0}$ \\
\hline 6 & $\begin{array}{l}\mathbf{I} \\
\mathbf{P}\end{array}$ & $\begin{array}{l}++ \\
\text { Patchy-granular }\end{array}$ & $\begin{array}{l}++ \\
\text { Beaded }\end{array}$ & 0 & 0 & $\mathbf{0}$ \\
\hline 7 & $\begin{array}{l}\mathbf{I} \\
\mathbf{P}\end{array}$ & $\begin{array}{l}++ \\
\text { Patchy-granular }\end{array}$ & $\begin{array}{l}++ \\
\text { Beaded }\end{array}$ & 0 & 0 & $\mathbf{0}$ \\
\hline \multicolumn{7}{|c|}{ Necropsies } \\
\hline 8 & $\begin{array}{l}\mathbf{I} \\
\mathbf{P}\end{array}$ & $\begin{array}{l}++ \\
\text { Patchy-granular }\end{array}$ & $\stackrel{+}{\text { Beaded }}$ & $\mathbf{0}$ & $\stackrel{+}{\text { Diffuse }}$ & $\mathbf{0}$ \\
\hline 9 & $\begin{array}{l}\mathbf{I} \\
\mathbf{P}\end{array}$ & $\begin{array}{l}++ \\
\text { Patchy-granular }\end{array}$ & $\begin{array}{l}++ \\
\text { Beaded }\end{array}$ & $\begin{array}{l}++ \\
\text { Diffuse }\end{array}$ & 0 & $\stackrel{+}{\text { Diffuse }}$ \\
\hline 10 & $\begin{array}{l}\mathbf{I} \\
\mathbf{P}\end{array}$ & $\begin{array}{l}++ \\
\text { Patchy-granular }\end{array}$ & $\begin{array}{l}++ \\
\text { Beaded }\end{array}$ & $\begin{array}{l}0 \text { to }++ \\
\text { Diffuse }\end{array}$ & $\stackrel{++}{\text { Diffuse }}$ & 0 \\
\hline 11 & $\begin{array}{l}\mathbf{I} \\
\mathbf{P}\end{array}$ & $\stackrel{+}{\text { Granular }}$ & $\stackrel{+}{\text { Beaded }}$ & 0 & $\stackrel{+}{\text { Diffuse }}$ & $\stackrel{++}{+}$ \\
\hline 12 & $\mathbf{I}$ & $\stackrel{+}{+}$ & $\stackrel{+}{\text { Beaded }}$ & 0 & $\begin{array}{l}++ \\
\text { Diffuse }\end{array}$ & 0 \\
\hline 13 & I & $\stackrel{+}{\text { Patchy-granular }}$ & $\stackrel{+}{\text { Beaded }}$ & $\mathbf{0}$ & o & $\mathbf{0}$ \\
\hline 14 & $\begin{array}{l}\mathbf{I} \\
\mathbf{P}\end{array}$ & $\stackrel{+}{\text { Patchy-granular }}$ & $\stackrel{+}{\text { Beaded }}$ & $\mathbf{0}$ & $\stackrel{+}{\text { Diffuse }}$ & 0 \\
\hline 15 & $\begin{array}{l}\mathbf{I} \\
\mathbf{P}\end{array}$ & $\stackrel{+}{\text { Granular }}$ & $\begin{array}{l}++ \\
\text { Diffuse }\end{array}$ & $\begin{array}{l}0 \text { to }++ \\
\text { Diffuse }\end{array}$ & $\begin{array}{l}++ \\
\text { Diffuse }\end{array}$ & $\stackrel{+}{\text { Diffuse }}$ \\
\hline 16 & I & $\begin{array}{l}++ \\
\text { Patchy-granular }\end{array}$ & $\begin{array}{l}++ \\
\text { Beaded }\end{array}$ & $\begin{array}{l}0 \text { to }++ \\
\text { Diffuse }\end{array}$ & $\stackrel{+}{+}$ & $\begin{array}{l}++ \\
\text { Diffuse }\end{array}$ \\
\hline
\end{tabular}

Table II Intensity and pattern of fluorescence ${ }^{1}$

${ }^{1}$ Grading of fluorescent intensity was on an arbitrary semiquantitative scale of $0,+$, and ++ . 'I $\mathbf{I}=$ intensity; $\mathbf{P}=$ pattern. 

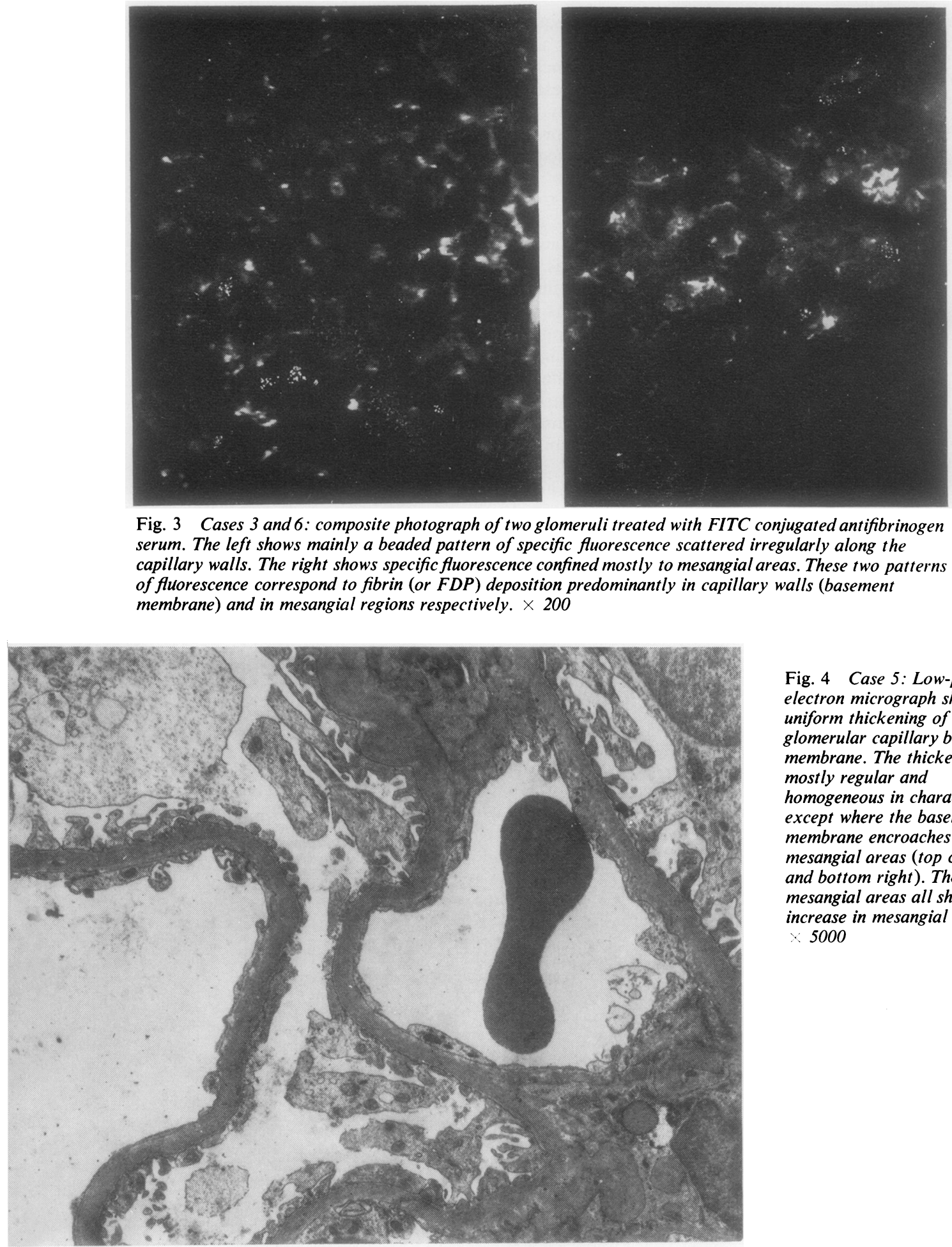

Fig. 4 Case 5: Low-power electron micrograph showing uniform thickening of glomerular capillary basement membrane. The thickening is mostly regular and homogeneous in character except where the basement membrane encroaches on mesangial areas (top centre and bottom right). The mesangial areas all show slight increase in mesangial matrix. 5000

Fig. 3 Cases 3 and 6: composite photograph of two glomeruli treated with FITC conjugated antifibrinogen serum. The left shows mainly a beaded pattern of specific fluorescence scattered irregularly along the capillary walls. The right shows specific fluorescence confined mostly to mesangial areas. These two patr
of fluorescence correspond to fibrin (or FDP) deposition predominantly in capillary walls (basement membrane) and in mesangial regions respectively. $\times 200$ 


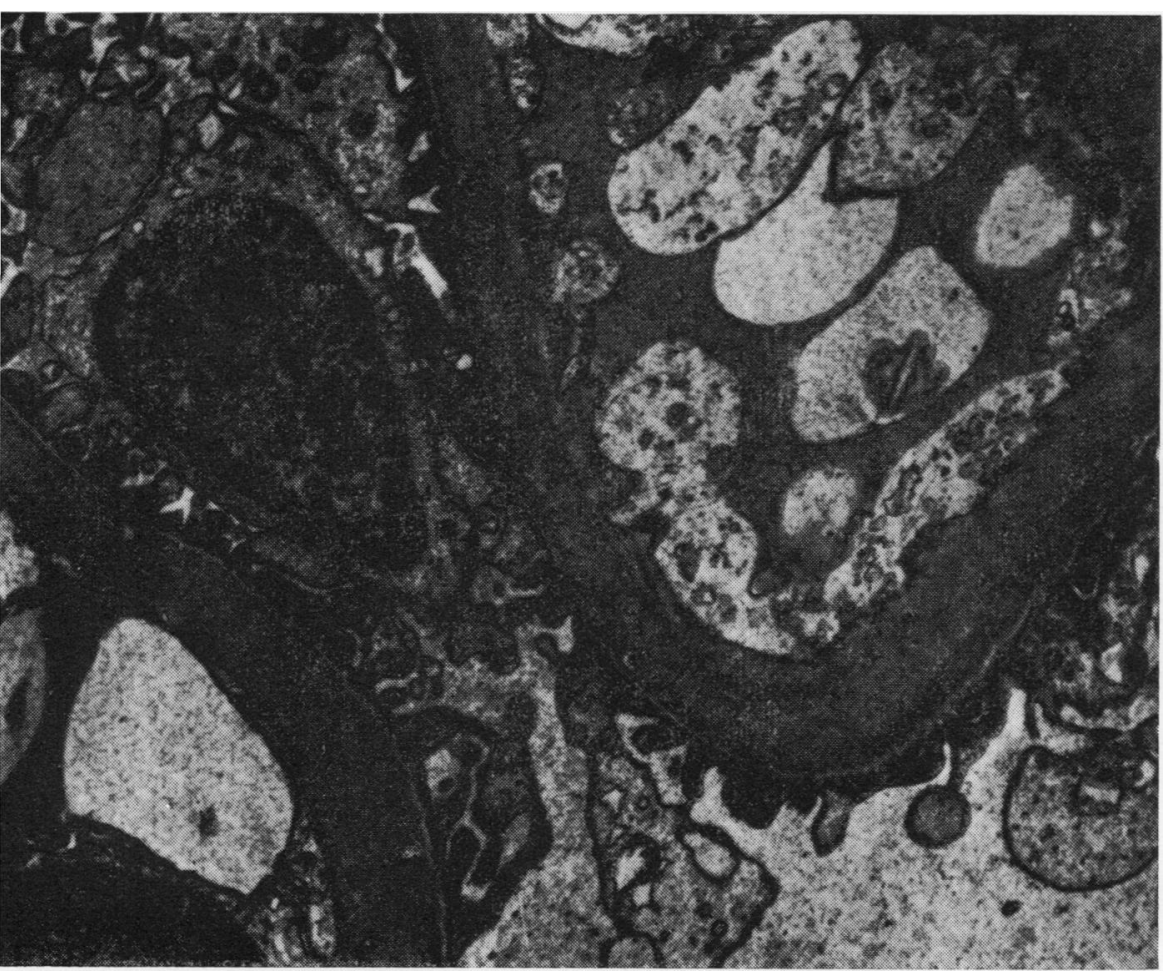

Fig. 8 Case 1: within the diffusely thickened basement membrane some areas show a linear distribution of darker staining material (upper right). Material of similar electron density is seen in the lumen between projections of endothelial cytoplasm (lower right). $\times 7000$

Fig. 9 Case 1: this shows a mesangial area with nucleus to the right and basement membrane uppermost. Scattered throughout the mesangial area are dark granular fibrillar deposits with an electron density varying from black to the lighter grey characteristic of basement membrane proper. The electrondense material within the mesangial area can be seen to merge imperceptibly with basement membrane proper at top right and to left of centre of plate. $\times 5800$ 
Fig. 10 Case 4: this demonstrates intraluminal material with a distinctly fibrillar structure (lower part of plate), merging gradually with basement membrane (upper part of plate). $\times 52500$

Fig. 11 Case 2: strands of granular-fibrillar material are seen in the capillary lumen and between projections of endothelial cytoplasm. The electron density of this material again varies from light grey, characteristic of basement membrane, to black. An endothelial nucleus is seen at bottom centre of photograph and scattered areas of endothelial cytoplasmic vacuolation are evident. $\times 7000$ 


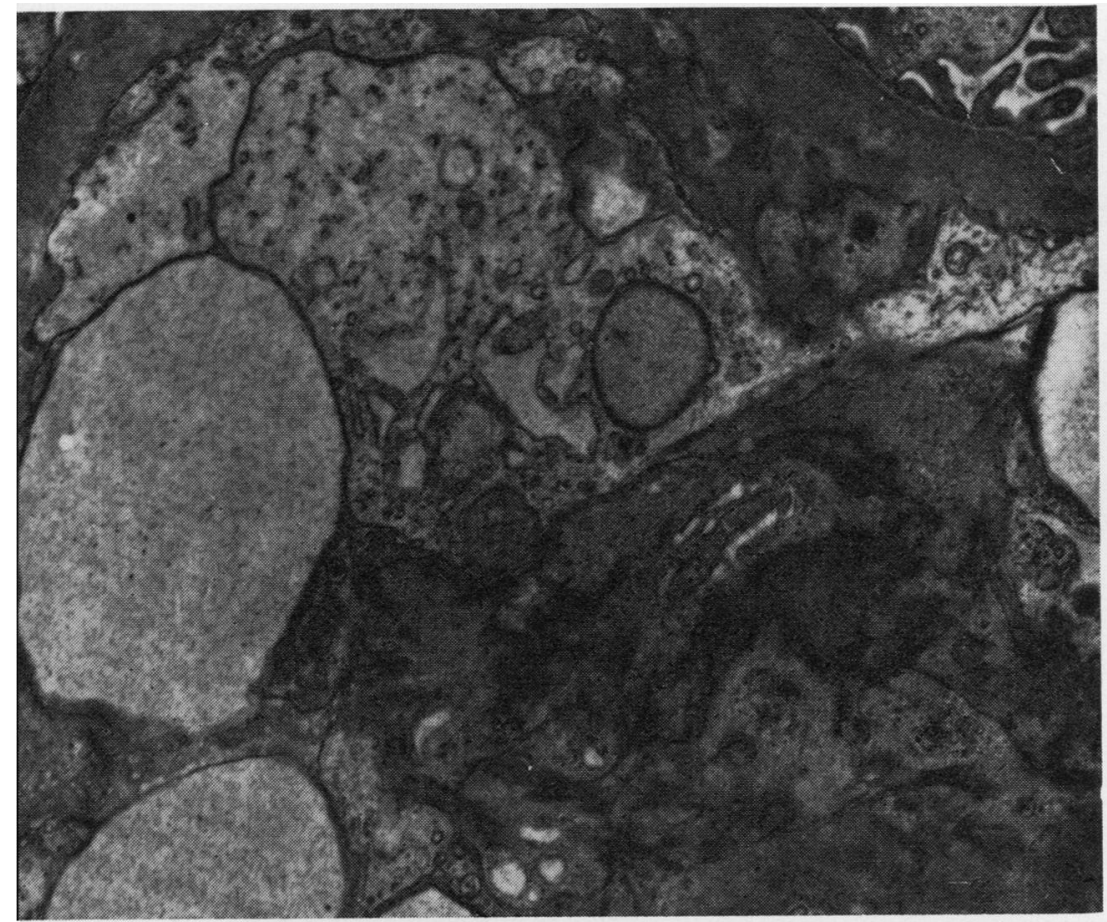

Fig. 12 Case 3: much granular fibrillar material of varying electron density can be seen scattered throughout the mesangial region (right). There is gross vacuolation of endothelial and possibly mesangial cytoplasm. Linear deposits of dark granular material can be seen throughout the basement membrane (especially left), and some granular material in a subendothelial location is seen to merge gradually with basement membrane (top). $\times 700$

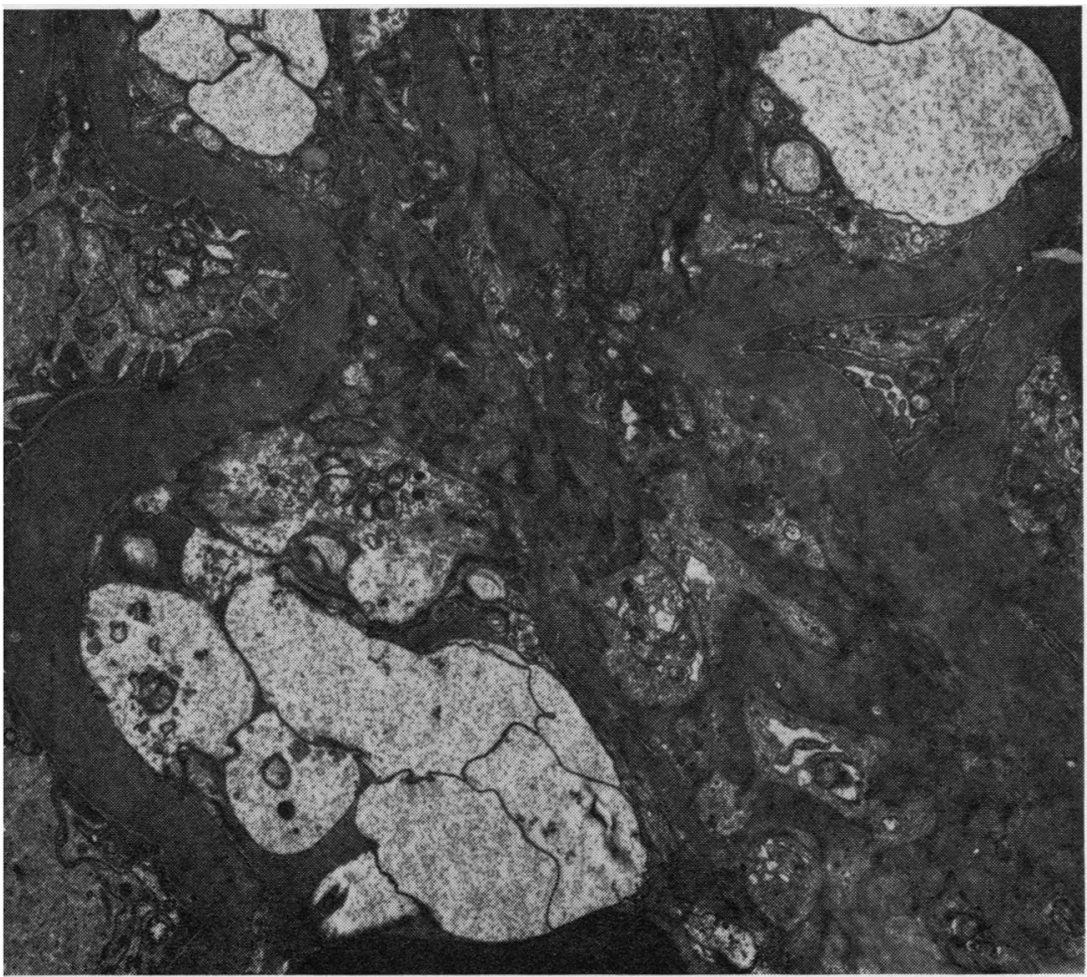

Fig. 13 Case 1: three capillary lumina are seen enclosing $a$ mesangial area and nucleus (nucleus top centre). In all, the endothelial cytoplasm is grossly vacuolated. One capillary lumen (bottom) contains much electron-dense, finely granulary material between projections of endothelial cytoplasm. The mesangial area in the centre of the photograph contains scattered granular deposits of varying electron density. Epithelial foot processes appear essentially normal. $\times 4400$ 
of appearances which this substance may assume. As Lendrum et al (1962) have shown on light microscopy using special stains, fibrin may go through a variety of appearances on electron microscopic examination, ranging from the dark, electron-dense nature of fresh fibrin to the lighter grey hyaline of older fibrin. Besides the difficulty of distinguishing fibrin from basement membrane-like hyaline, it is often impossible to distinguish the latter from basement membrane proper (Bencosme and Bergman, 1962). Stages of transition from a black, granular appearance through paler grey to typical hyaline basement membrane-like branches have been observed (Bloodworth, 1965a).

While fibrin having a periodicity of 200 to $240 \mathrm{~A}^{\circ}$ has not, to our knowledge, been described in the early stages of diabetic glomerulosclerosis, some investigators have made reference to amorphous, electron-dense granular deposits within the peripheral capillary basement membrane or within the mesangial areas in glomeruli not severely affected by other morphological change (Suzuki, Churg, Grishman, Mautner, and Dachs, 1963; Rosenbaum, Kattine, and Gottsegen, 1963; Dachs, Churg, and Mautner, 1964). Similar changes have been described in those few instances where glomerular lesions convincingly similar to human diabetic glomerulosclerosis have been produced in animals (Østerby Hansen, Lundbaek, Olsen, and Orskov, 1967; Bloodworth, 1965b; Gibbs, Wilson, and Gifford, 1966).

Although fully polymerized fibrin is, except in the later stages, a rarity in human lesions those electrondense granular deposits described above probably represent intermediate compounds in the fibrinogen to fibrin conversion; the fibrinogen-derived macromolecules now identified as fibrinogen degradation products (FDP). Their elusive nature possibly accounts for the rarity with which they have been identified on light and electron microscopy. Immunofluoresence microscopy with antifibrinogen serum is more highly specific, however, and gives a greater frequency of positive identification of FDP (Davies et al, 1966; Burkholder, 1965).

Until recently the concept of altered vascular permeability with early mural infiltration by mesometric substances, including fibrinogen, has received little support; Lendrum (1963), however, has consistently implicated fibrin in the pathogenesis of diabetic glomerulosclerosis. Whether deposition of fibrin or FDP in the diabetic glomerulus is of primary or secondary significance remains controversial. On the one hand it could be argued that such deposits are a secondary response to endothelial damage or represent the early stage of the exudative lesion. On the other hand, with more refined techniques for identifying fibrin and related pro- ducts, our findings suggest that fibrin deposition might be a primary event in the pathogenesis of diabetic glomerulosclerosis. While homogeneous thickening of the capillary basement membrane distinguishes diabetes from other causes of glomerulosclerosis (MacDonald, 1966), whether the lesion arises in the peripheral capillary loops or in the mesangium is still disputed (Kimmelstiel, Osawa, and Beres, 1966; MacSween, 1971). Nevertheless, the metabolic defect leading to increased basement membrane thickness may simultaneously alter the membrane permeability; thus, the increased glycolyzation of hydroxylysine units in the peptide chains of basement membrane from the diabetic subject (Beisswenger and Spiro, 1970) may diminish the of availability of the amino-acid to participate in $\%$ cross linkages. This biochemical defect, together with the presence of bulky carbohydrate components on the peptidechains, may increase basement membrane permeability. Although there is little doubt that fibrin aggregates can cause severe glomerular damage (Vassalli, Simon, and Rouilles, 1963; Prose et al, 1965; Beller, Mitchell, and Gorstein, 1967), it may be that altered basement membrane permeability $\vec{\theta}$ in diabetes mellitus together with a defect in fibrino- N lysis causes prolonged deposition of FDP in the glomerulus and ultimately stimulates structural changes whose nature depends on the pattern of distribution and rapidity of deposition of fibrinogen degradation products. One of our patients showed abnormal urinary FDP values in two of seven consecutive daily urine specimens. The other patients were not examined, however. Similar examination in other diabetic patients over a longer period of time has shown definitely increased urinary levels in some (Clarkson, 1971). Normal FDP levels, of course, are not inconsistent with slow or intermittent fibrin deposition or lysis. The local response to mesangial and endothelial trapping of fibrinogen or other 8 macromolecules may play some part in mesangial enlargement and basement membrane irregularity 음

besides initiating nodule development.
Despite attempts to explain the diabetic lesion on the basis of genetic, metabolic, immunological, $N$ endocrine or other factors, two significant aspects have never been adequately explained: first, the $\mathbb{O}$ focal and peripheral lobular situation of the Kim- N melstiel-Wilson nodule, and secondly the variability between accelerated microangiopathy in some dia- 0 betics and the relative freedom from such complica- $\frac{C}{\Phi}$ tions in others. Besides having relevance to nodule $\stackrel{\infty}{+}$ formation fibrin deposition and altered fibrinolysis 0 may be relevant also to the variability in diabetic $\bar{O}$ lesions. Important in this context may be the finding $\mathscr{\odot}$ of Cash and McGill (1969) who isolated a subgroup $\overrightarrow{\mathbb{D}}$ of diabetic subjects who had an impaired fibrinolytic 
response to stress. Possibly this finding indicates that some diabetic patients run a special risk of developing complications.

Certainly, diabetic small blood vessel disease cannot be composed into a straightforward picture. Whereas it would be unwise to stress any particular theory, however plausible, without considering the logical alternatives, it would seem that the focal structural and general metabolic relationships of fibrin deposition and fibrinolysis are worthy of further study in diabetes mellitus.

Financial support has been given by the Lawson Tait Medical and Scientific Research Trust, the Carnegie Trust for the Universities, the Secretary of State for Scotland, and the Scottish Hospitals Endowment Research Trust. Photographic reproductions are the work of J. Paul, Medical Photography Department, the University of Edinburgh. We are indebted to Drs L. J. P. Duncan and J. S. Robson for permission to study patients under their care.

\section{References}

Abastado, M., Doumenc, J., Prost, R., Bara, L., Samama, M., Dérot, M., and Bousser, J. (1968). Etude de l'activité fibrinolytique et des fonctions plaquettaires dans le premier temps de l'hémostase chezles diabetiques. Presse méd., 76, 1317-1320.

Balodimos, M. C., Gleason, R. E., Kahn, C. B., Chlouverakis, C., Jarret, R. J., Keen, H., and Soelder, J. S. (1971). Urinary albumin excretion in the offspring of conjugal diabetics. Lancet, 2, 239-242.

Beisswenger, P. J., and Spiro, R. G. (1970). Human glomerular basement membrane: chemical alteration in diabetes mellitus. Science, 168, 596-598.

Beller, F. K., Mitchell, P. S., and Gorstein, F. (1967). Fibrin deposition in the rabbit kidney produced by protease inhibitors. Thrombos. Diathes. haemorrh. (Stuttg.), 17, 427-439.

Bencosme, S. A., and Bergman, B. J. (1962). The ultrastructure of human and experimental glomerular lesions. Int. Rev. exp. Path., 1, 139-208.

Berkman, J., and Rifkin, H. (1966). Newer aspects of diabetic microangiopathy. Ann. Rev. Med., 17, 83-112.

Bloodworth, J. M. B., Jr. (1965a). Ultrastructural demonstration of basic similarities between human diabetic glomerulosclerosis, glomerulonephritis and systemic lupus erythematosus. (Abstr.). Diabetes, 14, 441-442.

Bloodworth, J. M. B., Jr. (1965b). Experimental diabetic glomerulosclerosis. II. The dog. Arch. Path., 79, 113-125.

Burkholder, P. M. (1965). Immunohistopathologic study of localized plasma proteins and fixation of guinea-pig complement in renal lesions of diabetic glomerulosclerosis. Diabetes, 14, 755770.

Cash, J. D., and McGill, R. C. (1969). Fibrinolytic response to moderate exercise in young male diabetics and non-diabetics. J. clin. Path., 22, 32-35.

Clarkson, A. R. (1971). Personal communication.

Clarkson, A. R., MacDonald, M. K., Petrie, J. J. B., Cash, J. D., and Robson, J. S. (1971). Serum and urinary fibrin/fibrinogen degradation products in glomerulonephritis. Brit. med. J., 3 , 447-451.

Dachs, S., Churg, J., Mautner, W., and Grishman, E. (1964). Diabetic nephropathy. Amer. J. Path., 44, 155-168.

Davies, M. J., Woolf, N., and Carstairs, K. C. (1966). Immunohistochemical studies in diabetic glomerulosclerosis. J. Path. Bact. 92, $441-445$.

Ditzel, J., and Schwartz, M. (1967). Renal function in young diabetics. (Letter). Lancet, 1, 276.

Egeberg, O. (1963). The blood coagulability in diabetic patients. Scand. J. clin. Lab. Invest., 15, 533-538.
Fearnley, G. R., Chakrabarti, R., and Avis, P. R. D. (1963). Blood fibrinolytic activity in diabetes mellitus and its bearing on ischaemic heart disease and obesity. Brit. med. J., 1, 921-923.

Fisher, E. R., Perez-Stable, E., Amıdi, M., Sarver, M. E., and Danowski, T. S. (1967). Ultrastructural renal changes in juvenile diabetics. J. Amer. med. Ass., 202, 291-295.

Gibbs, G. E., Wilson, R. B., and Gifford, H. (1966). Glomerulosclerosis in the long term alloxan diabetic monkey. Diabetes, 15,258 261.

Haust, M. D., Wyllie, J. C., and More, R. H. (1965). Electron microscopy of fibrin in human atherosclerotic lesions; immunohistochemical and morphologic identification. Exp. molec. Path., 4, 205-216.

Ireland, J. T. (1970). Diagnostic criteria in the assessment of glomerular capillary basement membrane lesions in newly diagnosed juvenile diabetics. In Early Diabetes, edited by R. A. CameriniDavalos and H. S. Cole, pp. 273-278. Academic Press, New York.

Ireland, J. T. (1971). Diabetic nephropathy. In Seventh Symposium on Advanced Medicine, edited by I. A. D. Bouchier, pp. 302-315. Pitman Medical, London.

Kimmelstiel, P., Osawa, G., and Beres, J. (1966). Glomerular basement membrane in diabetics. Amer. J. clin. Path., 45, 21-31.

Larsson, O. (1967). Studies of small vessels in patients with diabetes. A clinicai, histological and immunohistochemical study of diabetic and non-diabetic subjects with special reference to the occurrence of various plasma proteins in the dermal vessel walls. Acta med. scand., Suppl., 480.

Lendrum, A. C. (1963). The hypertensive diabetic kidney as a model of the so-called collagen diseases. Canad. med. Ass. J., 88, 442452.

Lendrum, A. C., Fraser, D. S., Slidders, W., and Henderson, R. (1962). Studies on the character and staining of fibrin. J. clin. Path., 15, 401-413.

McCluskey, R. T., and Vassalli, P. (1969). Experimental glomerular disease. In The Kidney, edited by C. Rouiller and A. F. Muller, vol. 2, pp. 83-198. New York.

MacDonald, M. K. (1966). Specificity of the glomerular lesion in diabetes mellitus. In Diabetes Mellitus (University of Edinburgh Pfizer Medical Monographs, No. 1), edited by L. J. P. Duncan, pp. 94-100. Edinburgh University Press, Edinburgh.

MacSween, R. N. M. (1971). Diabetic angiopathy. Scot. med. J., 16, 327-335.

Mayor, H. D., Hampton, J. C., and Rosario, B. (1961). A simple method for removing the resin from epoxy-embedded tissue. J. Biophys. and biochem. Cytol., 9, 909-910.

Nairn, R. C. (1969). Fluorescent Protein Tracing, 3rd edition, pp. 111 151. Livingstone, Edinburgh and London.

Østerby Hansen, R., Lundbaek, K., Olsen, T. S., and Ørskov, H. (1967). Kidney lesions in rats with severe long term alloxan diabetes. 3. Glomerular ultrastructure. Lab. Invest., 17, 675-692.

Prose, P. H., Lee, L., and Balk, S. D. (1965). Electron microscopic study of the phagocytic fibrin-clearing mechanism. Amer. J. Path., 47, 403-417.

Rosenbaum, P., Kattine, A. A., and Gottsegen, W. L. (1963). Diabetic and pre-diabetic nephropathy in childhood. Amer. J. Dis. Child., 106, 83-95.

Salinas-Madrigal, L., Pirani, C. L., and Pollock, V. E. (1970). Glomerular and vascular 'insudative' lesions of diabetic nephropathy: electron microscopic observations. Amer. J. Path., 59, 369-397.

Sharma, S. D., and Malhotra, P. P. (1969). Blood fibrinolytic activity in diabetes mellitus. Indian J. red. Sci., 23, 366-370.

Shaw, S., Pegrum, G. D., Wolf,, S., and Ashton, W. L. (1967). Platelet adhesiveness in diabetes mellitus. J. clin. Path., 20, 845847.

Suzuki, Y., Churg, J., Grishman, E., Mautner, W., and Dachs, S. (1963). The mesangium of the renal glomerulus. Electron microscopic studies of pathologic alterations. Amer. J. Path. 43, 555-578.

Trap-Jensen, J., Alpert, J. S., Garcia del Rio, and Lassen, N. A. (1967). Capillary diffusion capacity for sodium in skeletal muscle in long term juvenile diabetes mellitus. Acta med. scand., Suppl., 476, $135+$.

Valdorf-Hansen, F. (1967). Coagulability in diabetes. Acta med. scand., Suppl., 476, 147-158.

Vassalli, P., Simon, G., and Rouiller, C. (1963). Electron microscopic study of glomerular lesions resultirg from intravascular fibrin formation. Amer. J. Path., 43, 579-617. 